\title{
Optimizing Reservoir-Stream-Aquifer Interactions for Conjunctive Use and Hydropower Production
}

\author{
Hala Fayad, ${ }^{1}$ Richard C. Peralta, ${ }^{2}$ and Ali Forghani ${ }^{2}$ \\ ${ }^{1}$ Biological and Irrigation Engineering Department, Utah State University, Logan, UT 84322-4105, USA \\ ${ }^{2}$ Civil and Environmental Engineering Department, Utah State University, 4110 Old Main Hill Logan, UT 84322-4110, USA
}

Correspondence should be addressed to Richard C. Peralta, peralta.rc@gmail.com

Received 22 September 2011; Accepted 20 January 2012

Academic Editor: Kirk Hatfield

Copyright ( $) 2012$ Hala Fayad et al. This is an open access article distributed under the Creative Commons Attribution License, which permits unrestricted use, distribution, and reproduction in any medium, provided the original work is properly cited.

Conjunctive management of water resources involves coordinating use of surface water and groundwater resources. Very few simulation/optimization (S-O) models for stream-aquifer system management have included detailed interactions between groundwater, streams, and reservoir storage. This paper presents an S-O model doing that via artificial neural network simulators and genetic algorithm optimizer for multiobjective conjunctive water use problems. The model simultaneously addresses all significant flows including reservoir-stream-diversion-aquifer interactions in a more detailed manner than previous models. The model simultaneously maximizes total water provided and hydropower production. A penalty function implicitly poses constraints on state variables. The model effectively finds feasible optimal solutions and the Pareto optimum. Illustrated is application for planning water resource and minihydropower system development.

\section{Introduction}

Conjunctive management of water resources involves coordinating use of surface water and groundwater resources, often to address demands of competing water users. Conjunctive management can reduce temporal water deficits by using groundwater when surface water supplies are scarce. Where surface water and groundwater resources are hydraulically connected, understanding the interaction between the two resources is important.

Water resources management cannot be optimized without the ability to simulate the system's response to management and hydrologic stimuli. Simulation models predict physical system response to natural and managed stimuli. On the other hand, a simulation-optimization (S-O) model directly computes the water management strategy that best satisfies desired goals without causing unacceptable system responses. It employs user-specified objectives to drive the search for an optimal strategy.

The embedding technique and response matrix approach are the two methods generally used to incorporate groundwater simulation abilities within an S-O model [1-6]. For transient problems in which relatively few cells include decision or state variables, the response matrix method is more practical and has been generally used.

The response matrix method relies upon linear systems theory and superposition [7]. Confined aquifers are linear systems. Nonlinear systems, such as unconfined aquifers, can also be treated as linear if changes in saturated thickness and transmissivity in time are proportionally small with respect to initial values [8]. Many researchers adopted linear treatment to satisfactorily address nonlinear systems $[5,6,9-11]$. Others used cycling or sequential linear programming (SLP) to adapt linear systems theory to address nonlinear groundwater problems [2-4, 6, 12-14].

Most reported conjunctive use of S-O models uses classical optimizers relying upon simplex and gradient search approaches. O'Mara and Duloy [15] used an agricultural production economic model to plan management of a riveraquifer system. Walker [16] coordinated surface water and groundwater systems serving independent irrigation areas. Peralta et al. [17, 18] and Da Conceicao Morais et al. [19] used crop production functions to allocate surface water and groundwater. Ejaz and Peralta [20] optimized conjunctive 
use with surface water quality constraints. Belaineh et al. [11] included reservoir management rules and detailed interactions between reservoir storage and releases, surface water diversions, and groundwater pumping. Barlow et al. [5] evaluated tradeoffs between groundwater withdrawal and streamflow depletion.

Because most conjunctive use problems are nonlinear, classical nonlinear programming optimizers have been used often [18, 21-25]. However, because the convexity of the objective function and feasible region cannot always be ensured, global optimality of computed solutions is not always guaranteed. Furthermore, the process of computing derivatives can consume much CPU time.

Consequently, researchers employed heuristic optimizers that do not require computing derivatives. Such methods include simulated annealing $[23,26]$, and Genetic Algorithms (GAs) [27-38].

Heuristic optimizers are coupled with groundwater and other simulation models. Both normal numerical finite simulators and surrogate simulators are used. Surrogates such as artificial neural networks (ANNs) are used to reduce computational burden during optimization. ANNs are trained using field data or a calibrated numerical model. A trained ANN simulates much more quickly than the original numerical model.

Rogers et al. [30] used GA optimization with substitute simulators, artificial neural networks (ANNs). The ANNs suitably represented state variable response to management. Rao et al. [23] used SA with ANNs to perform combinatorial optimization for simple nonlinear, nonconvex, conjunctive use allocation. Karamouz et al. [33] addressed conjunctive use and water quality using GAs and ANNs. Safavi et al. [37] used an ANN to represent surface water-groundwater interaction and a GA to minimize unsatisfied demand in three irrigation systems. However, they did not consider reservoir storage.

Some of the above efforts involved multiple measures of performance or objectives that could be optimized simultaneously. Multiple objective (MO) optimization permits evaluating tradeoffs between conflicting goals and aids identifying acceptable compromise solutions. When considering all objectives simultaneously in MO problems, a set of solutions exists that are superior to all other solutions in the search space. The superior solutions are known as "Pareto Optimal" solutions or "Non Dominated" solutions [39, 40].

This paper presents a multiobjective simulation/optimization model that uses artificial neural networks simulation, GA optimization, and constraints for optimizing conjunctive use of a nonlinear hydraulically linked reservoir-streamaquifer system. Trained using results of simulations from a spatially distributed finite difference simulation model, the ANNs represent groundwater head, reservoir level and stream stage, response to boundary conditions, and the water management strategy being optimized. State variables are discouraged from having undesirable values by penalty functions. Penalty functions are usually derived from experience and are subject to imprecision and uncertainty. Decision variables include spatially distributed groundwater pumping, reservoir diversion, stream diversion, and reservoir
TABle 1: Parameters associated with the streams, lake, and aquifer.

\begin{tabular}{|c|c|}
\hline Parameters & Values \\
\hline \multicolumn{2}{|l|}{ Reservoir/lake } \\
\hline Area & $2.3 \times 10^{6} \mathrm{~m}^{2}$ \\
\hline Capacity & $42 \times 10^{6} \mathrm{~m}^{3}$ \\
\hline Cutoff elevation & $29.5 \mathrm{~m}$ \\
\hline Turbine elevation & $20.0 \mathrm{~m}$ \\
\hline Initial stage & $29.0 \mathrm{~m}$ \\
\hline Diversion channel capacity & $14115 \mathrm{~m}^{3} /$ day \\
\hline Penstock Capacity (release to hydropower) & $200,000 \mathrm{~m}^{3} /$ day \\
\hline Hydraulic Conductivity of lakebed & $0.04 \mathrm{~m} /$ day \\
\hline Thickness of lakebed sediment & $0.9 \mathrm{~m}$ \\
\hline \multicolumn{2}{|l|}{ Streams } \\
\hline Width & $9.1 \mathrm{~m}$ \\
\hline Thickness of streambed sediment & $0.3 \mathrm{~m}$ \\
\hline Slope of streambed segments & 0.0002 \\
\hline $\begin{array}{l}\text { Hydraulic conductivity of } \\
\text { streambed sediment }\end{array}$ & $0.04 \mathrm{~m} /$ day \\
\hline Manning's roughness coefficient & 0.02 \\
\hline Streambed conductance & $180 \mathrm{~m}^{2} /$ day \\
\hline \multicolumn{2}{|l|}{ Stream inflow to lake } \\
\hline Total length & $6090 \mathrm{~m}$ \\
\hline Inflows in stress period 1 & $225840 \mathrm{~m}^{3} /$ day \\
\hline Inflows in stress period 2 & $56460 \mathrm{~m}^{3} /$ day \\
\hline Inflows in stress period 3 & $112920 \mathrm{~m}^{3} /$ day \\
\hline \multicolumn{2}{|l|}{ Stream outflow from lake } \\
\hline Total length & $2435 \mathrm{~m}$ \\
\hline First diversion channel capacity & $8750 \mathrm{~m}^{3} /$ day \\
\hline Second diversion channel capacity & $14115 \mathrm{~m}^{3} /$ day \\
\hline \multicolumn{2}{|l|}{ Aquifer } \\
\hline Hydraulic conductivity of unconfined layer & $61 \mathrm{~m} /$ Day \\
\hline Specific yield of the unconfined layer & 0.15 \\
\hline Transmissivity of the confined layer & $371 \mathrm{~m}^{2} /$ day \\
\hline Storage coefficient of the confined layer & 0.0001 \\
\hline $\begin{array}{l}\text { Ratio of horizontal to vertical hydraulic } \\
\text { conductivity }\end{array}$ & 100 \\
\hline Groundwater recharge & $0.8 \times 10^{-3} \mathrm{~m} /$ day \\
\hline Precipitation rate & $2.2 \times 10^{-3} \mathrm{~m} /$ day \\
\hline Evaporation rate & $1.74 \times 10^{-3} \mathrm{~m} /$ day \\
\hline Irrigated field & $650 \times 10^{3} \mathrm{~m}^{2}$ \\
\hline
\end{tabular}

release rates. The linked ANN-GA model robustly addresses multiple objectives for a complicated nonlinear reservoirstream-aquifer system and includes more significant flows than previously reported ANN-based models (Table 1 and Figure 1).

\section{Study Area}

The proposed model is applied to a hypothetical study area based upon that of Cheng and Anderson [41], modified to more comprehensively illustrate conjunctive use issues. 


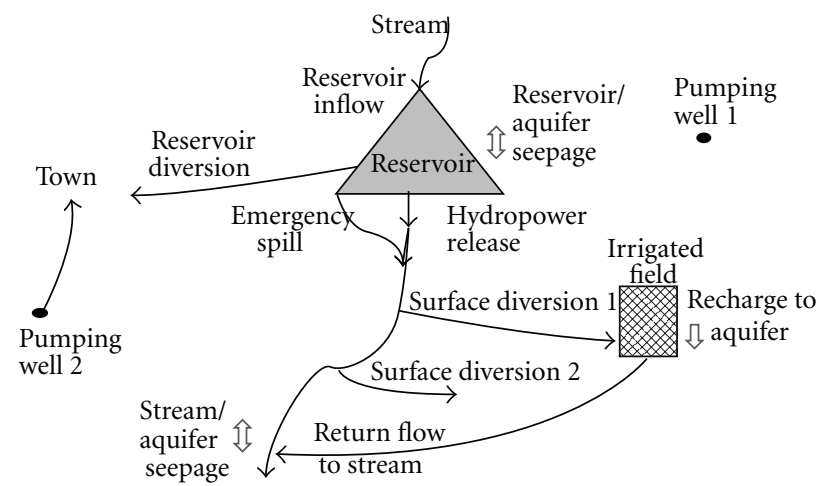

Figure 1: Conceptual view of the hypothetical study area.

TABLE 2: Water demands in the study area.

\begin{tabular}{lccc}
\hline Water user & Characteristic & Source & Demand $\left(\mathrm{m}^{3} / \mathrm{day}\right)$ \\
\hline Industry 1 & & Pumping well-1 & 1660 \\
Industry 2 & & Reservoir diversion & 1383 \\
Industry 3 & & Pumping well-2 & 4150 \\
Industry 4 & & Stream diversion-2 & 1245 \\
Irrigated area & $650,000 \mathrm{~m}^{2}$ & Stream diversion-1 & 3873 \\
Town & 600 persons & Pumping well-2 and reservoir diversion & 180 \\
\hline
\end{tabular}

The area includes an influent stream, multipurpose reservoir and discharges, effluent stream and diversions, groundwater extraction wells, and municipal, industrial, and irrigation users (Figure 1). Wells pump from a homogeneous anisotropic two-layer aquifer system represented by a finite difference model (Figure 2). The total study area size is $11.15 \times$ $10^{6} \mathrm{~m}^{2}$.

The Figure 3 conceptual cross-section illustrates the saturated hydraulic connection between the $18.2 \mathrm{~m}$ deep reservoir and the aquifer. The $9.1 \mathrm{~m}$ wide stream is in excellent hydraulic connection with the aquifer and penetrates only the unconfined layer. Wells extract only from the confined aquifer layer. From the reservoir, flows one diversion and a release that passes through turbines, producing hydropower before re-entering the stream. Table 1 data show that the reservoir can provide a maximum head of $9.5 \mathrm{~m}(29.5 \mathrm{~m}$ cutoff elevation minus $20 \mathrm{~m}$ ). Table 1 also contains other distinguishing characteristics and parameters of the study area.

Table 2 shows different industrial, municipal, and irrigation water demands in the region and identifies sources that can satisfy them. The irrigated area receives water from the first stream diversion. The reservoir diversion, the second stream diversion, and the pumping wells deliver water to four industrial areas and one small rural town. Conveyance losses are insignificant because water flows through new pipes and lined concrete canals. The four industrial and municipal users either consume water completely or discharge unconsumed water outside the study area after treatment. Assumed losses for the irrigated area total 30 percent of applied water (18 percent percolates as recharge to the unconfined aquifer and 12 percent returns to the stream as return flow).

\section{Methodology}

\subsection{Simulation of Reservoir-Stream-Aquifer Interactions}

3.1.1. Introduction. The artificial neural networks used here are trained to produce some of the same outputs as a finite difference numerical simulation model. After training, the ANNs are embedded within the presented S-O model. The GA heuristic optimizer uses the ANNs during optimization, rather than using the finite difference model. The following explanation of the process begins by discussing the original simulator.

3.1.2. Direct Simulation Using Finite Difference Model. Initially employed to simulate reservoir-stream-aquifer flows is the USGS MODFLOW finite difference groundwater flow model [42], with the LAK2 lake package [43], and STR stream routing package [44]. LAK2 simulates reservoirgroundwater interaction and reservoir water stage. STR computes flow in the stream, stream stage, and stream-aquifer seepage. Seepage is a function of stream stage and aquifer head. Together, these are termed the MODLAKE model. MODLAKE simulated the system under transient conditions using three sixty-day stress periods and Table 1 parameter values.

Input values for MODLAKE simulations include pumping rates at wells 1 and 2, stream diversion rates 1 and 2, reservoir diversion, and reservoir release. For 3 stress periods, these total 18 values. For each period, seven important computed output system states descriptors are heads at both wells in both confined and unconfined strata, stream stage at two control locations, and reservoir stage. 
1

5

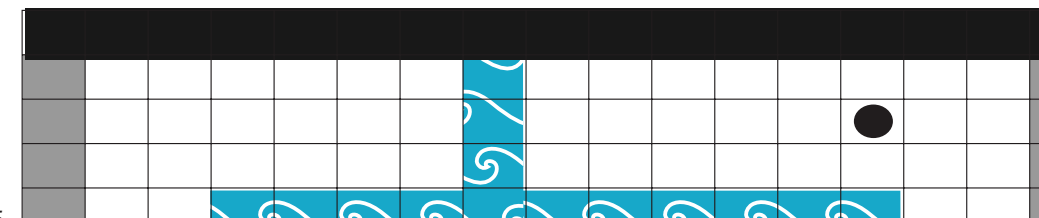

10

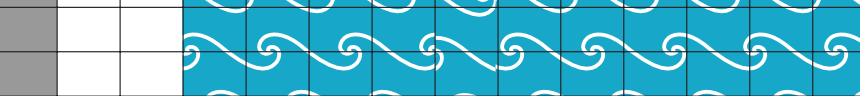

(G) G G G G G G

15

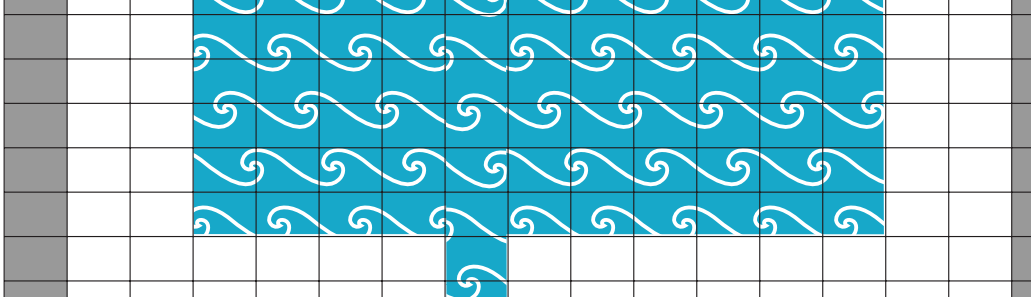

20

25

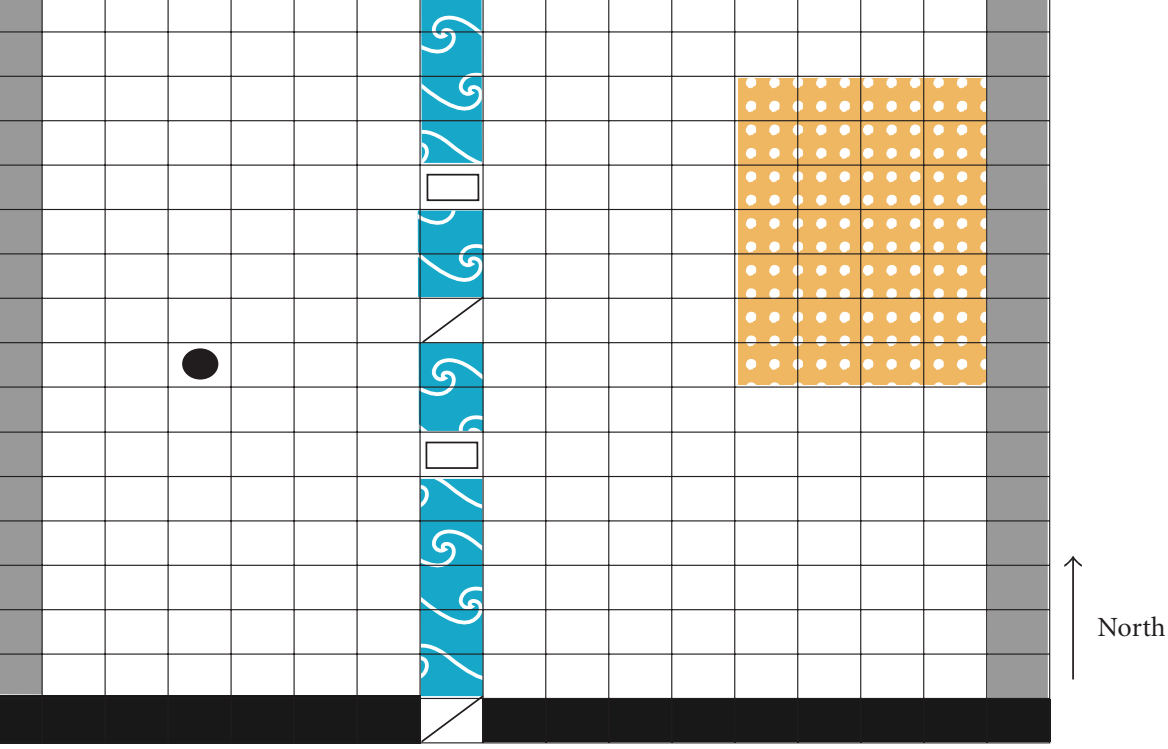

Constant head cells

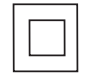

Surface water diversion

Stream/lake cells

No-flow cells

Groundwater

pumping cells

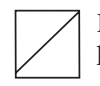

Flow control location

Irrigated field

FIGURE 2: Discretization and cell types of the hypothetical study area.

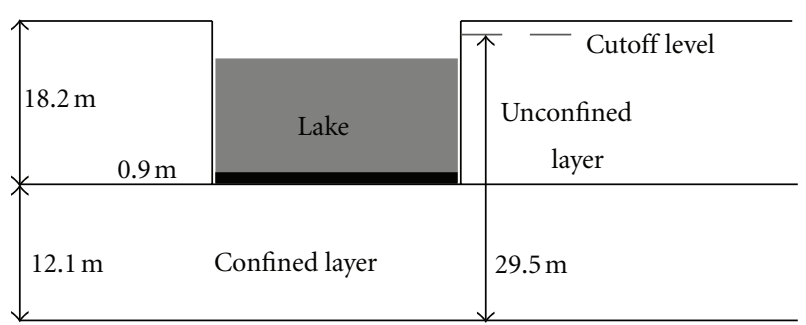

FIGURE 3: Distorted cross section of study area at reservoir location. 
TABLE 3: Evaluation results for 7 ANNs in stress period 1.

\begin{tabular}{lccc}
\hline State variable & Number of nodes in ANN & Correlation $R$ & Ratio of test to training RMS \\
\hline Lake stage & $6-6-1$ & 0.999 & 1.049 \\
Head 1 layer 1 & $6-4-1$ & 0.998 & 0.804 \\
Head 2 layer 1 & $6-4-1$ & 0.992 & 0.416 \\
Head 1 layer 2 & $6-6-1$ & 0.999 & 0.488 \\
Head 2 layer 2 & $6-8-1$ & 0.995 & 0.366 \\
Stream stage 1 & $6-7-1$ & 0.901 & 1.183 \\
Stream stage 2 & $6-3-1$ & 0.968 & 0.812 \\
\hline
\end{tabular}

The discharge from the reservoir that can occur via the emergency spillway is not a model input value. Occurring only when reservoir stage is above the Table 1 cut-off value, it flows to the stream (Figure 1). That discharge is computed via rating equation:

$$
Q_{\text {emergency, } k}=\text { Const } \times\left[h_{\text {lake }, k}-\text { Cut-off elevation }\right]^{\text {Exponent }},
$$

where Const and Exponent parameter values are 1385649 and 1.66667, respectively. These values are obtained following Cheng and Anderson [41] where stream outflow is governed by Manning's equation.

\subsubsection{Indirect Simulation Using Artificial Neural Networks.}

To develop the data base for ANN training, many MODLAKE simulations were performed for a range of input flow values. For each simulation, the above-mentioned 18 flow values were inputs, and 21 state variables were recorded outputs. Note that, during subsequent optimization, the S-O model will determine optimal values for these 18 decision variables, and will ensure that these 21 state variables have satisfactory values.

One ANN was trained to represent each of the 21 state variables. Table 3 shows the number of input, hidden, and output nodes for ANNs describing period 1 state variables. Because there are six input flows in period one, Table 3 shows that the input layer has six nodes. The number of hidden nodes within the ANN hidden layer was determined through trial and error. Because a separate ANN was developed for each state variable, there is only one output node per ANN.

Networks for the first stress period were developed using input data from the first stress period only (six input nodes corresponding to six decision variables). Networks for the second stress period were developed using input data from the first and second stress periods. Therefore, all networks in this period had 12 input nodes, corresponding to 12 decision variables. Networks for the third period required 18 input nodes.

Here, the NeuralSIM commercial package was used to train and validate the 21 ANNs for the 21 state variables. NeuralSIM uses the cascade method of network construction with an adaptive gradient learning rule. The back-propagation learning method was used.

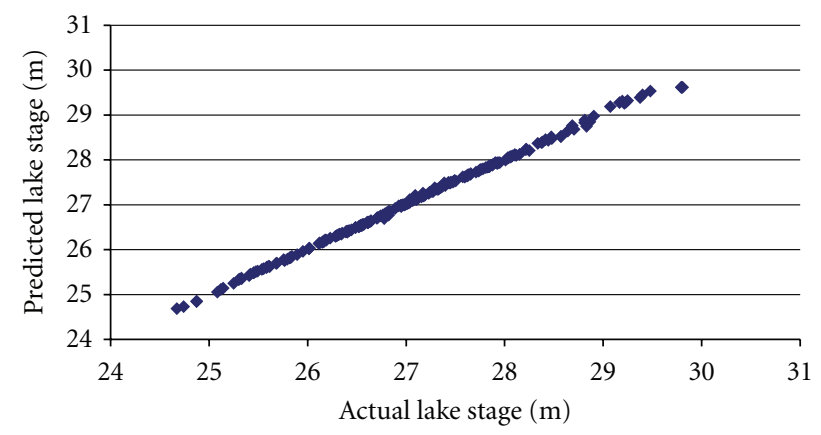

FIGURE 4: ANN-predicted versus actual lake stage.

To adequately train ANNs for the highly nonlinear reservoir-stream-aquifer system, many data were used. About 400 sets of decision variables were created randomly within a broad range, and the same number of MODLAKE simulations was performed. Then, additional 300 sets of decision variables were developed for a narrow range, and were simulated using MODLAKE. The combined sets of decision and state variables constituted the ANN training data.

Training involves adjusting ANN parameters until ANN output is close to desired (target) values. The above MODLAKE output provided the target values. According to NeuralSIM, an indicator of an adequate ANN is that training set performance and test set performance are fairly similar. Figure 4 displays ANN-predicted versus MODLAKE-simulated (actual) lake stage in stress period 1.

Two means of comparing ANN and MODLAKE outputs were used linear correlation $(R)$ and root mean squared error (RMS).

Linear correlation values were 0.875 to 0.999 for all ANNs. This high correlation indicates that the real-world target is highly explained by the ANN-predicted values. Also, for almost all networks, the ratio of the RMS of the test data to the RMS of the training data was less than 1.45. Table 3 provides the evaluation results for 7 ANNs in stress period 1 . Hsu et al. [45] showed detail ANN training.

3.2. Optimization Problem. Water resources allocation problems can involve complicated hydrological, environmental, and economical constraints and conflicting management 
objectives. The posed study area has adequate water supply for existing water uses, but planners want to evaluate best to increase water use while producing hydropower. These two objectives conflict.

3.2.1. Water Supply Objective. For an area relying on an aquifer and a stream for its water supply, the objective is to maximize the water provided from pumping wells and from surface diversions. Surface diversions include both diversions from streams and diversions from surface water reservoirs. Equation (2) is the objective function of maximizing water provided to users:

$$
Z_{1}=\operatorname{Max}\left(\frac{1}{T}\right) \sum_{k=1}^{T}\left[\sum_{\hat{\mathrm{a}}=1}^{N^{P}} C_{\hat{\mathrm{a}}, k}^{P} p_{\hat{\mathrm{a}}, k}+\sum_{\hat{\mathrm{e}}=1}^{N^{S}} C_{\hat{\mathrm{e}}, k}^{S} d_{\hat{\mathrm{e}}, k}^{\mathrm{str}}+\sum_{\hat{\mathrm{i}}=1}^{N^{R}} C_{\hat{\mathrm{i}}, k}^{R} d_{\hat{\mathrm{i}}, k}^{\mathrm{res}}\right],
$$

where $Z_{1}$ is the average flow rate delivered during all periods, $p_{\hat{a}, k}$ is the rate of water pumped from cell â during period $k, d_{\hat{\mathrm{e}}, k}^{\mathrm{str}}$ is the rate of stream water diverted at diversion point $\hat{\mathrm{e}}$ during period $\mathrm{k}$, and $d_{\hat{\mathrm{i}}, k}^{\mathrm{res}}$ is the rate of reservoir water diverted at diversion point $\hat{i}$ during time period $k . N^{P}, N^{S}$, and $N^{R}$ are total numbers of groundwater pumping, stream diversions, and reservoir diversions, respectively. $C_{\hat{\mathrm{a}}, k}^{P}, C_{\hat{\mathrm{e}}, k}^{D}$, and $C_{\hat{i}, k}^{R}$ are weighting coefficients assigned to groundwater pumping, stream diversion, and reservoir diversion, respectively.

Optimal solutions are sensitive to the weighting coefficients. Careful selection of coefficient values permits their use for economic optimization and emphasizing or deemphasizing specific decision variables. A variable can be made ineffective in the objective function by setting its respective weighting coefficient equal to zero.

3.2.2. Hydropower Production Objective. Water released from the lake through a turbine produces hydropower as per the following:

$$
\text { Hydropower }=e_{p} \gamma \frac{Q_{h p, k}}{86,400} h_{g, k},
$$

where Hydropower is in kilowatts $(\mathrm{kw}), e_{p}$ is the overall efficiency of the power plant (the product of hydraulic and turbine efficiencies), $\gamma$ is the specific weight of water $\left(9.81 \mathrm{KN} / \mathrm{m}^{3}\right), Q_{h p, k}$ is the reservoir release flow rate $\left(\mathrm{m}^{3} / \mathrm{d}\right)$, and $h_{g}$ is the gross head difference between the reservoir water surface and the point where water passes through the turbine $(\mathrm{m})$.

Rearranging yields (4), the objective function for maximizing the average hydropower produced during the management era:

$$
Z_{2}=\operatorname{Max} e_{p} \gamma \times \sum_{k=1}^{T}\left(\left(\frac{Q_{h p, k}}{86,400}\right)\left(h_{\text {lake }, k}-h_{\text {turbine }}\right)\left(\frac{1}{T}\right)\right),
$$

where, for this site, $e_{p}$ is $0.65, h_{\text {turbine }}$ is the elevation of the point where water passes through the turbine $(20 \mathrm{~m})$, and $h_{\text {lake, } k}$ is the lake stage at end of time period $k$.
TABLE 4: Bounds on decision variables in stress period 1.

\begin{tabular}{lcc}
\hline Decision variable & $\begin{array}{c}\text { Lower bound }(\mathrm{L}) \\
\left(\mathrm{m}^{3} / \text { day }\right)\end{array}$ & $\begin{array}{c}\text { Upper bound }(\mathrm{U}) \\
\left(\mathrm{m}^{3} / \text { day }\right)\end{array}$ \\
\hline Pumping well 1 & 310 & 2820 \\
Pumping well 2 & 30 & 8460 \\
Stream diversion 1 & 75 & 8460 \\
Stream diversion 2 & 360 & 2820 \\
Reservoir diversion & 28 & 2820 \\
Reservoir release & 57680 & 195370 \\
\hline
\end{tabular}

3.2.3. Bounds and Constraints. Constraints enforce physical laws, legal rights, and management goals. The most simple constraints are lower and/or upper bounds on decision variables (Table 4). Upper limits on well pumping rates assure that pumpage from a given well does not exceed the capacity of the well, pump, and pipe. Upper limits on reservoir and stream diversions prevent exceeding the capacity of the diversion canals. Lower limits on stream diversions consider legal rights. The upper bound on reservoir release $\left(Q_{h p, k}\right)$ equals the smaller of the turbine capacity and the penstock capacity. The lower bound reflects legal or economic reasons.

More complicated constraints involving decision variables are demand constraints and constraints limiting total stream diversion. Demand constraints ensure that total water delivered to each user at least satisfies existing demand:

$$
\sum_{k=1}^{T}\left(p_{\hat{\mathrm{a}}, k}+d_{\hat{\mathrm{e}}, k}^{\mathrm{str}}+d_{\hat{\mathrm{i}}, k}^{\mathrm{res}}\right) \geq \sum_{k=1}^{T} \operatorname{Demand}_{k},
$$

where Demand $d_{k}$ is the total current demand for water in time period $k$. The intent is to possibly provide more water for future development.

Upper bounds on cumulative stream diversions downstream of the reservoir ensure that stream diversions do not exceed the available water in the stream. In other words, the sum of stream diversions downstream of the reservoir must be always less than or equal the reservoir release to the stream.

Each state variable that must be bounded during optimization is represented within the S-O model as an ANN. The GA represents their bounds using the penalty method. Table 5 shows the imposed bounds on state variables.

Limits on reservoir stage ensure that the water does not bypass the turbine and that the reservoir does not face environmental dangers:

$$
h_{\text {lake, }, k}^{\mathrm{L}} \leq h_{\text {lake, } k} \leq h_{\text {lake }, k}^{\mathrm{U}} .
$$

To prevent unacceptable drawdown, the hydraulic head in the aquifer at each well $\hat{a}$ should be within lower (L) and upper (U) bounds for each time period:

$$
h_{\widehat{\mathrm{a}}, k}^{\mathrm{L}} \leq h_{\widehat{\mathrm{a}}, k} \leq h_{\mathrm{a}, k}^{\mathrm{U}} .
$$

Lower limit on stream stage at each control location $\widehat{\mathrm{u}}$ ensures adequate flow for recreational, navigational, legal, and environmental reasons:

$$
\operatorname{stage}_{\widehat{\mathrm{u}}, k} \geq \operatorname{stage}_{\widehat{\mathrm{u}}, k}^{\mathrm{L}} .
$$




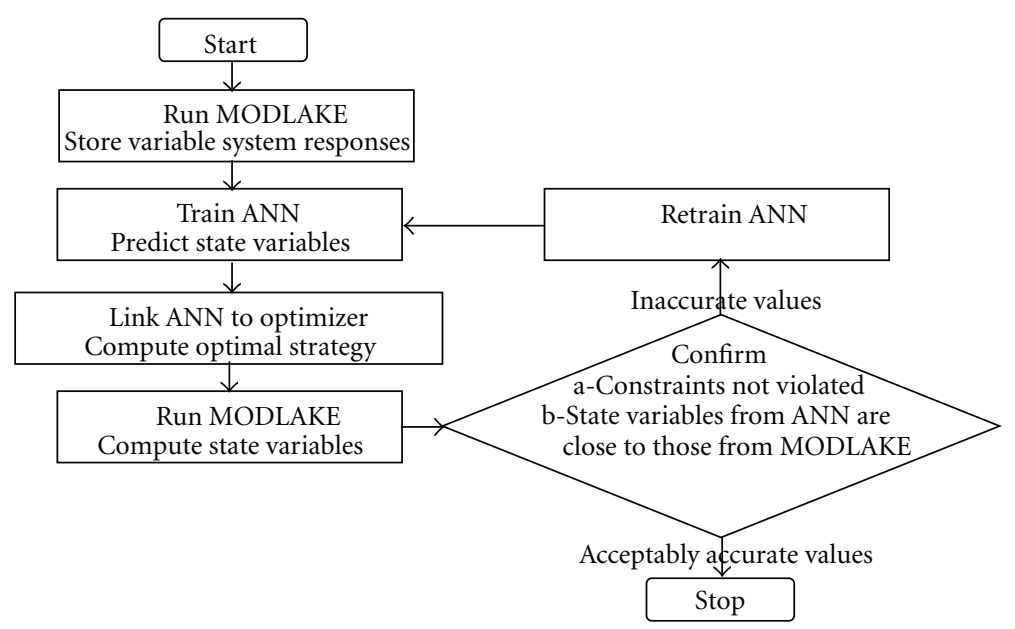

FIGURE 5: S-O model processing.

TABLE 5: Bounds on state variables.

\begin{tabular}{|c|c|c|}
\hline Constraint & Equation & Constraint \\
\hline \multicolumn{3}{|l|}{ Stress period 1} \\
\hline 1 (Lake stage) & 8 & $25.1 \leq$ lake stage $\leq 29.3 \mathrm{~m}$ \\
\hline $2($ Head 1 layer 1$)$ & 6 & $26.2 \leq$ head 1 layer $1 \leq 30.2 \mathrm{~m}$ \\
\hline $3($ Head 2 layer 1$)$ & 6 & $22.9 \leq$ head 2 layer $1 \leq 29 \mathrm{~m}$ \\
\hline $4($ Head 1 layer 2$)$ & 6 & $20.7 \leq$ head 1 layer $2 \leq 29 \mathrm{~m}$ \\
\hline 5 (Head 2 layer 2$)$ & 6 & $17.1 \leq$ head 2 layer $2 \leq 27.1 \mathrm{~m}$ \\
\hline 6 (Stream stage 1$)$ & 7 & $20.5 \leq$ stream stage $1 \leq 20.6 \mathrm{~m}$ \\
\hline 7 (Stream stage 2) & 7 & $20.2 \leq$ stream stage $2 \leq 20.3 \mathrm{~m}$ \\
\hline \multicolumn{3}{|l|}{ Stress period 2} \\
\hline 8 (Lake stage) & 8 & $21.9 \leq$ lake stage $\leq 29.6 \mathrm{~m}$ \\
\hline $9($ Head 1 layer 1$)$ & 6 & $21.9 \leq$ head 1 layer $1 \leq 28 \mathrm{~m}$ \\
\hline $10($ Head 2 layer 1$)$ & 6 & $20.6 \leq$ head 2 layer $1 \leq 27.1 \mathrm{~m}$ \\
\hline 11 (Head 1 layer 2) & 6 & $16.5 \leq$ head 1 layer $2 \leq 26.5 \mathrm{~m}$ \\
\hline 12 (Head 1 layer 2) & 6 & $15.2 \leq$ head 2 layer $2 \leq 26.2 \mathrm{~m}$ \\
\hline 13 (Stream stage 1 ) & 7 & $20 \leq$ stream stage $1 \leq 20.1 \mathrm{~m}$ \\
\hline 14 (Stream stage 2) & 7 & $19.7 \leq$ stream stage $2 \leq 19.8 \mathrm{~m}$ \\
\hline \multicolumn{3}{|l|}{ Stress period 3} \\
\hline 15 (Lake stage) & 8 & $22.6 \leq$ lake stage $\leq 28 \mathrm{~m}$ \\
\hline 16 (Head 1 layer 1$)$ & 6 & $18.9 \leq$ head 1 layer $1 \leq 27.4 \mathrm{~m}$ \\
\hline 17 (Head 2 layer 1$)$ & 6 & $18.9 \leq$ head 2 layer $1 \leq 25.6 \mathrm{~m}$ \\
\hline 18 (Head 1 layer 2) & 6 & $14.3 \leq$ head 1 layer $2 \leq 25.3 \mathrm{~m}$ \\
\hline 19 (Head 2 layer 2) & 6 & $14.6 \leq$ head 2 layer $2 \leq 24.4 \mathrm{~m}$ \\
\hline 20 (Stream stage 1 ) & 7 & $19.9 \leq$ stream stage $1 \leq 20 \mathrm{~m}$ \\
\hline 21 (Stream stage 2) & 7 & $19.7 \leq$ stream stage $2 \leq 19.8 \mathrm{~m}$ \\
\hline
\end{tabular}

3.3. Genetic Algorithm and Modeling Methodology. Genetic algorithms (GAs) can be powerful and robust optimizers for nonlinear problems, if using appropriate optimization parameters and enough simulations. A simple genetic algorithm (SGA) is a search procedure based on the mechanics of natural selection and genetics. It uses selection and recombination operations while searching a solution space to identify the best solution. SGAs have been generally applied to singleobjective optimization problems.
However, many optimization problems have multiple objectives. When optimizing with GAs, multiple objectives have usually been addressed by either combining all objectives into a scalar objective function (consisting of a sum of weighted multiple objectives) or by converting some objectives into constraints having thresholds and penalty functions. Other methods for handling multiple objectives include $\varepsilon$-constraint method, goal programming, and Multi objective genetic algorithms (MOGAs).

The complexity of conjunctive use problems has led some researchers to use MOGAs. MOGAs also facilitate linking nonlinear optimizers and groundwater quantity and quality simulators. An efficient MOGAs is the nondominated sorting genetic algorithm (NSGA) [46]. NSGA uses a ranking selection method to emphasize current nondominated (Pareto optimal) points and a sharing function method to maintain diversity in the population.

For simulation, the presented model uses coupled ANN and finite difference simulation to represent more detailed flow interactions, than other reported models for multiobjective reservoir-stream-aquifer system management. The SO model uses NSGA for optimization. It includes objective or fitness functions, constraints, 21 linked ANNs, and the optimization algorithm. Using the optimizer requires setting five parameters values properly. These are mutation probability $\left(P_{\text {mutate }}\right)$, cross-over probability $\left(P_{\text {cross }}\right)$, niche size $\left(\sigma_{\text {share }}\right)$, population size, and maximum number of generations. $\sigma_{\text {share }}$ is dependent on the number of peaks in the solution space. We used a mutation probability of 0.01 and a cross-over rate of 0.6. The stopping criterion was 500 generations. The initial population size was 2758 individuals. The number of considered peaks was 100 . These values were derived via sizing criteria suggested by Mahfoud [47] and sensitivity analysis. Continuous decision variables were represented by binary coding. NSGA selection of strategies employed the stochastic remainder proportionate method [46].

Figure 5 shows the simulation/optimization modeling procedure. 
TABLE 6: Residual errors (MODLAKE minus ANN-GA) for five tested strategies.

\begin{tabular}{|c|c|c|c|c|c|}
\hline & Test $1(\mathrm{~m})$ & Test $2(\mathrm{~m})$ & Test $3(\mathrm{~m})$ & Test $4(\mathrm{~m})$ & Test $5(\mathrm{~m})$ \\
\hline \multicolumn{6}{|l|}{ Stress period 1} \\
\hline Lake stage & -0.06 & -0.04 & -0.09 & -0.08 & -0.08 \\
\hline Head 1 layer 1 & -0.13 & -0.1 & -0.13 & -0.11 & -0.14 \\
\hline Head 2 layer 1 & -0.08 & -0.06 & -0.08 & -0.09 & -0.1 \\
\hline Head 1 layer 2 & 0.2 & 0.2 & 0.2 & 0.13 & 0.22 \\
\hline Head 2 layer 2 & -0.13 & -0.1 & -0.15 & -0.22 & -0.25 \\
\hline Stream stage 1 & 0.0 & 0.0 & 0.0 & 0.0 & 0.0 \\
\hline Stream stage 2 & 0.0 & 0.0 & 0.0 & 0.0 & 0.0 \\
\hline \multicolumn{6}{|l|}{ Stress period 2} \\
\hline Lake stage & 0.02 & 0.08 & 0.05 & 0.03 & 0.06 \\
\hline Head 1 layer 1 & -0.01 & 0.08 & -0.04 & 0 & -0.04 \\
\hline Head 2 layer 1 & 0.18 & 0.18 & 0.05 & 0.08 & 0.08 \\
\hline Head 1 layer 2 & -0.08 & 0.1 & -0.03 & -0.1 & -0.05 \\
\hline Head 2 layer 2 & 0.08 & 0.06 & 0.04 & 0.09 & 0.07 \\
\hline Stream stage 1 & 0.02 & 0.03 & 0.02 & 0.02 & 0.02 \\
\hline Stream stage 2 & 0.04 & 0.03 & 0.04 & 0.04 & 0.04 \\
\hline \multicolumn{6}{|l|}{ Stress period 3} \\
\hline Lake stage & -0.02 & 0.05 & 0.03 & 0.02 & 0.04 \\
\hline Head 1 layer 1 & -0.5 & -0.29 & -0.43 & -0.45 & -0.49 \\
\hline Head 2 layer 1 & -0.15 & 0.09 & 0.00 & -0.03 & 0.08 \\
\hline Head 1 layer 2 & -0.32 & -0.16 & -0.22 & -0.24 & -0.21 \\
\hline Head 2 layer 2 & -0.42 & -0.35 & -0.36 & -0.35 & -0.35 \\
\hline Stream stage 1 & -0.01 & -0.01 & -0.02 & -0.02 & -0.02 \\
\hline Stream stage 2 & 0.01 & 0.03 & 0.03 & 0.02 & 0.03 \\
\hline
\end{tabular}

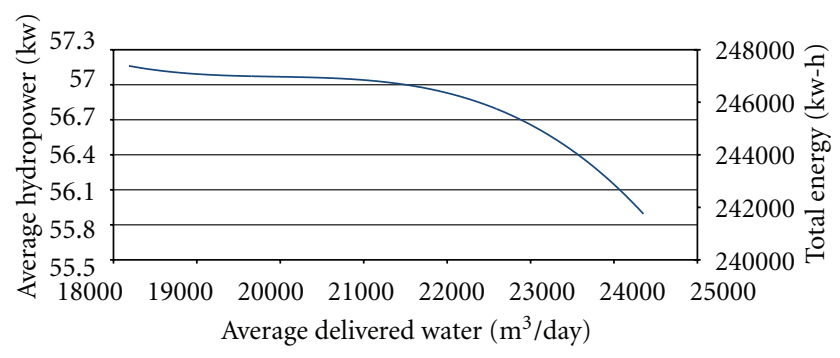

FIGURE 6: Average delivered water versus produced hydropower and energy.

(1) Generate numerous water management strategies. Each strategy is a set of pumping, diversions, and reservoir release rates. Run MODLAKE for each strategy. Store variable system responses for all stress periods.

(2) Using strategies and results of step 1, train an ANN to enable it to predict state variable response to other sets of decision variables.

(3) Apply the S-O model to compute optimal strategies. The model calls the ANN trained in step 2.

(4) Confirm that output strategies indeed satisfy all constraints. This is necessary because the ANNs are not perfectly accurate. To do this, run MODLAKE for the optimal water management strategies and check the state variable results.

\section{Results and Discussion}

The new S-O model is applied to the hypothetical study area discussed previously. The coupling of finite difference and neural networks to optimize all interactions of a reservoirstream-aquifer system is unique. Here, the aim is to maximize water supply and hydropower production simultaneously. The first objective (2) maximizes average water provided from pumping wells, stream diversions, and reservoir diversion. The weighting coefficient for each component was 1.0, emphasizing all decision variables equally. The second objective function (4) maximizes hydropower production by maximizing reservoir releases thru the turbine.

The two objectives are noncommensurate and conflicting. Maximizing provided water leads to maximizing water diverted from the reservoir. Therefore, the amount of water available for the turbine to produce hydropower decreases. This leads to a drop in hydropower production.

Figure 6 shows the trade-off (Pareto optimum) curve between the two objectives. Providing the most water produces the least average power and total energy.

Figure 5 suggests that, after optimization, one must confirm that the proposed model predicts system responses with acceptable accuracy. To do this, five Pareto optimal strategies were used as inputs to MODLAKE. All tested state variables satisfied the constraints listed in Table 5, meaning that optimal strategies are mathematically feasible and considered implementable. Table 6 contrasts ANN optimizer and MODLAKE outputs. Negative values in Table 6 
indicate networks overestimating state variable values. The maximum absolute error for all networks and all tests is $0.5 \mathrm{~m}$, corresponding to the head in the unconfined layer at well 1 during the third stress period. Since this state variable is constrained between 18.9 and $27.4 \mathrm{~m}$, the error $0.5 \mathrm{~m}$ constitutes $5.8 \%$. The slight lake stage inaccuracy affects hydropower production. The maximum error among all tests was $1.03 \mathrm{KW}$. For this demonstration, that is acceptable.

Results show the ability of the presented S-O model to find optimal solutions that will not violate constraints. This shows penalty function method effectiveness for handling constraints for multiobjective optimization.

\section{Conclusion}

This paper presents a simulation-optimization (S-O) model based on artificial neural networks and genetic algorithms for solving multiobjective nonlinear, conjunctive use problems. The model simultaneously addresses all significant flows and represents reservoir-stream-aquifer-diversion interactions in a more detailed manner than previously reported models. Using trained ANNs as state variable simulators is adequately accurate. The model robustly developed the tradeoff curve between the objectives of maximizing provided water and hydropower production. The S-O model identified optimal solutions that would not violate system constraints.

\section{Acknowledgment}

This research was supported by the Utah Agricultural Experiment Station, Utah State University, and approved as journal paper number 8344 .

\section{References}

[1] S. M. Gorelick, "A review of distributed parameter groundwater management modeling methods," Water Resources Research, vol. 19, no. 2, pp. 305-319, 1983.

[2] R. C. Peralta and A. Aly, "US/REMAX Utah State model for optimizing management of stream/aquifer systems using the response matrix method," Tech. Rep., BIE Department, Utah State University, Logan, Utah, USA, 1993.

[3] A. Gharbi and R. C. Peralta, "Integrated embedding optimization applied to Salt Lake Valley aquifers," Water Resources Research, vol. 30, no. 3, pp. 817-832, 1994.

[4] S. Takahashi and R. C. Peralta, "Optimal perennial yield planning for complex nonlinear aquifers: methods and examples," Advances in Water Resources, vol. 18, no. 1, pp. 49-62, 1995.

[5] p. M. Barlow, D. p. Ahlfeld, and D. C. Dickerman, "Conjunctive-management models for sustained yield of stream-aquifer systems," Journal of Water Resources Planning and Management, vol. 129, no. 1, pp. 35-48, 2003.

[6] D. Pulido-Velazquez, D. Ahlfeld, J. Andreu, and A. Sahuquillo, "Reducing the computational cost of unconfined groundwater flow in conjunctive-use models at basin scale assuming linear behaviour: the case of Adra-Campo de Dalías," Journal of Hydrology, vol. 353, no. 1-2, pp. 159-174, 2008.

[7] H. J. Morel-Seytoux, "A simple case of conjunctive surface groundwater management," Ground Water, vol. 13, no. 6, pp. 506-515, 1975.
[8] T. E. Reilly, O. L. Frank, and G. D. Benett, The Principle of Superposition and Its Application in Groundwater Hydraulics, US Government Printing Office, Washington, DC, USA, 1987.

[9] L. Jones, R. Willis, and W. W. G. Yeh, "Optimal control of nonlinear groundwater hydraulics using differential dynamic programming," Water Resources Research, vol. 23, no. 11, pp. 2097-2106, 1987.

[10] F. A. Mueller and J. W. Male, "A management model for specification of groundwater withdrawal permits," Water Resources Research, vol. 29, no. 5, pp. 1359-1368, 1993.

[11] G. Belaineh, R. C. Peralta, and T. C. Hughes, "Simulation/optimization modeling for water resources management," Journal of Water Resources Planning and Management, vol. 125, no. 3, pp. 154-161, 1999.

[12] D. p. Ahlfield and A. E. Mulligan, Optimal Management of Flow in Groundwater Systems, Academic Press, San Diego, Calif, USA, 2000.

[13] R. C. Peralta, B. Timani, and R. Das, "Optimizing safe yield policy implementation," Water Resources Management, vol. 25, no. 2, pp. 483-508, 2011.

[14] R. C. Peralta and I. M. Kalwij, Groundwater Optimization Handbook, Taylor and Francis Publishers, New York, NY, USA.

[15] T. G. O’Mara and J. H. Duloy, "Modeling efficient conjunctive use of water in the Indus Basin," in Efficiency in Irrigation The Conjunctive Use of Surface Water and Groundwater Resources, G. T. O'Mara, Ed., p. 196, A world Bank Symposium, Washington, DC, USA, 1988.

[16] W. R. Walker, "Integrating strategies for improving irrigation system design and management. Water management synthesis II," Tech. Rep. 70, Department of Agricultural and Irrigation Engineering, Utah State University, Logan, Utah, USA, 1990.

[17] R. C. Peralta, K. Kowalski, and R. R. A. Cantiller, "Maximizing reliable crop production in a dynamic stream/aquifer system," Transactions of the American Society of Agricultural Engineers, vol. 31, no. 6, pp. 1729-1736, 1988.

[18] R. C. Peralta, A. Gharbi, L. S. Willardson, and A. W. Peralta, "Optimal conjunctive use of ground and surface waters," in Management of Farm Irrigation Systems, chapter 12, pp. 426458, ASAE, 1990.

[19] p. Da Conceicao Morais, p. Hubert, and D. Tyteca, "Optimal management of a groundwater system for seasonally varying agricultural production," Water Resources Research, vol. 29, no. 7, pp. 2415-2426, 1993.

[20] M. S. Ejaz and R. C. Peralta, "Maximizing conjunctive use of surface and ground water under surface water quality constraints," Advances in Water Resources, vol. 18, no. 2, pp. 67-75, 1995.

[21] R. Willis and W. G. Yeh, Groundwater Systems Planning and Management, Prentice-Hall, Englewood Cliffs, NJ, USA, 1987.

[22] J. Matsukawa, B. A. Finney, and R. Willis, "Conjunctive-use planning in Mad River Basin, California," Journal of Water Resources Planning \& Management, vol. 118, no. 2, pp. 115-132, 1992.

[23] S. V. N. Rao, S. M. Bhallamudi, B. S. Thandaveswara, and G. C. Mishra, "Conjunctive use of surface and groundwater for coastal and deltaic systems," Journal of Water Resources Planning and Management, vol. 130, no. 3, pp. 255-267, 2004.

[24] M. Pulido-Velázquez, J. Andreu, and A. Sahuquillo, "Economic optimization of conjunctive use of surface water and groundwater at the basin scale," Journal of Water Resources Planning and Management, vol. 132, no. 6, pp. 454-467, 2006.

[25] L. Bharati, C. Rodgers, T. Erdenberger et al., "Integration of economic and hydrologic models: exploring conjunctive 
irrigation water use strategies in the Volta Basin," Agricultural Water Management, vol. 95, no. 8, pp. 925-936, 2008.

[26] D. M. Rizzo and D. E. Dougherty, "Characterization of aquifer properties using artificial neural networks: neural kriging," Water Resources Research, vol. 30, no. 2, pp. 483-497, 1994.

[27] D. C. McKinney and M.-D. Lin, "Genetic algorithm solution of groundwater management models," Water Resources Research, vol. 30, no. 6, pp. 1897-1906, 1994.

[28] B. J. Ritzel, J. W. Eheart, and S. Ranjithan, "Using genetic algorithms to solve a multiple objective groundwater pollution containment problem," Water Resources Research, vol. 30, no. 5, pp. 1589-1603, 1994.

[29] L. L. Rogers and F. U. Dowla, "Optimization of groundwater remediation using artificial neural networks with parallel solute transport modeling," Water Resources Research, vol. 30, no. 2, pp. 457-481, 1994.

[30] L. L. Rogers, F. U. Dowla, and V. M. Johnson, "Optimal fieldscale groundwater remediation using neural networks and the genetic algorithm," Environmental Science and Technology, vol. 29, no. 5, pp. 1145-1155, 1995.

[31] SSOL, SOMOS: Simulation/Optimization Modeling System, User's Manual, Systems Simulation, Optimization Laboratory, Department of Biological and Irrigation Engineering, Utah State University, Logan, Utah, USA, 2003.

[32] R. C. Peralta, I. M. Kalwij, and S. Wu, "Practical simulation/ optimization modeling for groundwater quality and quantity management," in Proceedings of the MODFLOW and MORE 2003: Understanding through Modeling Conference, pp. 784788, Poeter, Zheng, Hill \& Doherty, Golden, Colo, USA, 2003.

[33] M. Karamouz, M. M. Rezapour Tabari, R. Kerachian, and B. Zahraie, "Conjunctive use of surface and groundwater resources with emphasis on water quality," in Proceedings of the World Water and Environmental Resources Congress, vol. 173, p. 360, May 2005.

[34] M. Karamouz, M. M. R. Tabari, and R. Kerachian, "Application of genetic algorithms and artificial neural networks in conjunctive use of surface and groundwater resources," Water International, vol. 32, no. 1, pp. 163-176, 2007.

[35] M. Karamouz, B. Zahraie, R. Kerachian, and A. Eslami, "Crop pattern and conjunctive use management: a case study," Irrigation and Drainage, vol. 59, no. 2, pp. 161-173, 2010.

[36] M. R. Bazargan-Lari, R. Kerachian, and A. Mansoori, "A conflict-resolution model for the conjunctive use of surface and groundwater resources that considers water-quality issues: a case study," Environmental Management, vol. 43, no. 3, pp. 470-482, 2009.

[37] H. R. Safavi, F. Darzi, and M. A. Mariño, "Simulationoptimization modeling of conjunctive use of surface water and groundwater," Water Resources Management, vol. 24, no. 10, pp. 1965-1988, 2010.

[38] A. Afshar, A. Zahraei, and M. A. Mariño, "Large-scale nonlinear conjunctive use optimization problem: decomposition algorithm," Journal of Water Resources Planning and Management, vol. 136, no. 1, Article ID 002001QWR, pp. 59-71, 2010.

[39] V. Chankong and Y. Y. Haimes, Multiobjective Decision Making Theory and Methodology, North-Holland, New York, NY, USA, 1983.

[40] A. E. Hans, "Multicriteria optimization for highly accurate systems," in Multicriteria Optimization in Engineering and Sciences, Mathematical Concepts and Methods in Science and Engineering, W. Stadler, Ed., vol. 19, pp. 309-352, Plenum Press, New York, NY, USA, 1988.
[41] X. Cheng and M. p. Anderson, "Numerical simulation of ground-water interaction with lakes allowing for fluctuating lake levels," Ground Water, vol. 31, no. 6, pp. 929-933, 1993.

[42] A. W. Harbaugh and M. G. McDonald, "User's documentation for MODFLOW-96, an update to the U.S. Geological Survey modular finite-difference ground-water flow model," U.S. Geological Survey Open-File Report 96-485, 1996.

[43] G. W. Council, A Lake Package for MODFLOW (LAK2)Documentation and User's Manual, HSI Geotrans-A Tetra Tech Company, Sterling, Va, USA, 1999.

[44] D. E. Prudic, "Documentation of a computer program to simulate stream-aquifer relations using a modular, finite-difference, ground-water flow model," U.S. Geological Survey Open-File Report 88-729, 1989.

[45] K.-L. Hsu, H. V. Gupta, and S. Sorooshian, "Artificial neural network modeling of the rainfall-runoff process," Water Resources Research, vol. 31, no. 10, pp. 2517-2530, 1995.

[46] N. Srinivas and K. Deb, "Multiobjective optimization using Nondominated sorting in genetic algorithms," Journal of Evolutionary Computation, vol. 2, no. 3, pp. 221-248, 1994.

[47] S. W. Mahfoud, "Population size and genetic drift in fitness sharing," in Foundations of Genetic Algorithms, D. Whitley and M. D. Vose, Eds., pp. 185-224, Morgan Kaufmann, San Francisco, Calif, USA, 3rd edition, 1995. 

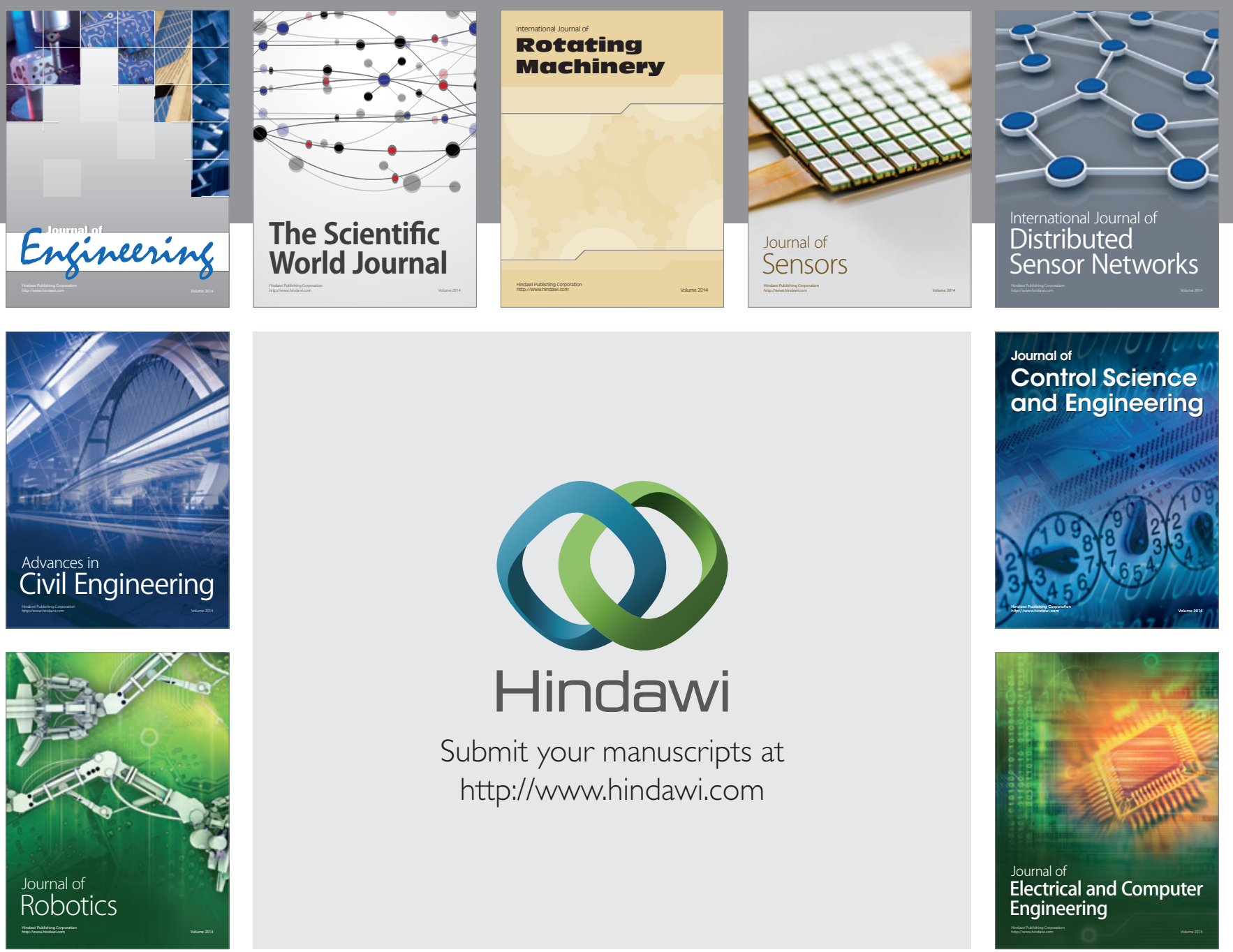

Submit your manuscripts at

http://www.hindawi.com
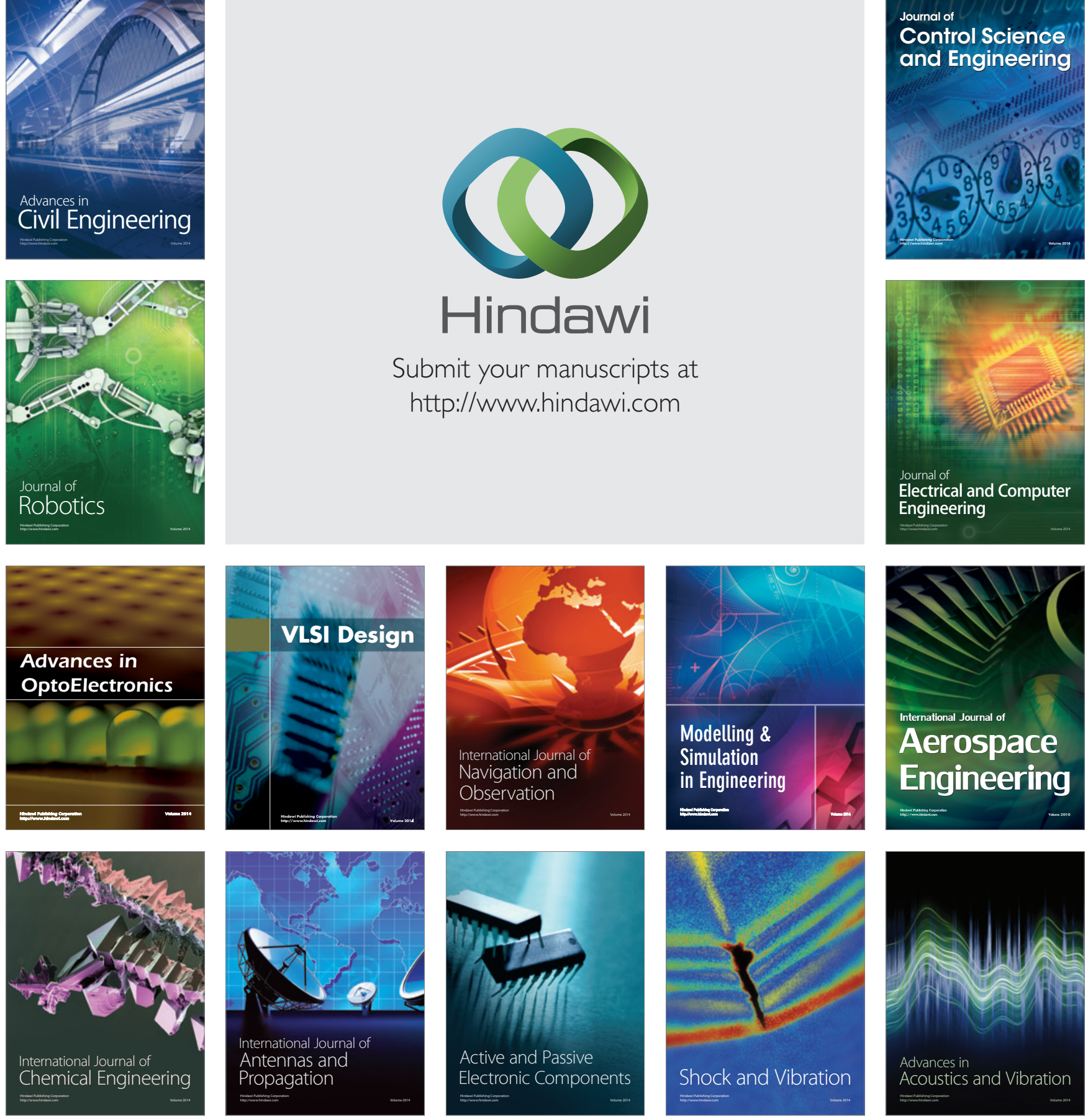